\title{
AN UNCOMMOM CASE OF A LARGE GARTNER'S CYST PRESENTING AS DYSPAREUNIA
}

\author{
Sumit H. Paranjpe ${ }^{1}$, Amaraja Agashe ${ }^{2}$, Haripandit E. Paranjpe ${ }^{3}$
}

${ }^{1}$ Consultant, Department of Obstetrics \& Gynaecology, Paranjpe Maternity Hospital, Mumbai. ${ }^{2}$ Senior Resident, Department of Obstetrics \& Gynaecology, D. Y. Patil Hospital, Navi Mumbai. ${ }^{3}$ Consultant \& Director, Paranjpe Maternity Hospital, Mumbai.

\section{ABSTRACT}

Gartner duct cysts are the remnants of the Wolffian duct and are uncommon in adulthood. Most of the mesonephric (Wolffian) ducts degenerate, some remnants may persist in the mesovarium where they form the epoophoron and paroophoron. The mesonephric cysts known as Gartner duct cysts are seen in $1 \%-2 \%$ of the women. Diagnosis is usually made with pelvic examination. Here, we present a case of $33 \mathrm{yr}$. old woman with the chief complaints of dyspareunia and a prolapsing vaginal mass. A diagnosis of Gartner's duct cyst was made after pelvic examination and ultrasonography. Surgical marsupialization was done with a histopathology report consistent with a Gartner's cyst.

\section{KEYWORDS}

Gartner's duct cyst. Dyspareunia, Prolapsing mass, Marsupialisation.

HOW TO CITE THIS ARTICLE: Sumit H. Paranjpe, Amaraja Agashe, Haripandit E. Paranjpe. "An Uncommom Case of a Large Gartner's Cyst Presenting as Dyspareunia." Journal of Evolution of Medical and Dental Sciences 2015; Vol. 4, Issue 99, December 10; Page: 16485-16486, DOI: $10.14260 /$ jemds/2015/2448

\section{INTRODUCTION}

Vaginal cysts are not frequently reported in literature, but are probably more common in daily practice.[1] Gartner's cysts are usually asymptomatic and most commonly diagnosed on routine gynecologic examination, but patient complaints can include that of skin tag, dysuria, boggyness, itching, dyspareunia, pelvic pain or protrusion from the vagina if it enlarges to a detectable size making surgery inevitable.[2]

Gartner duct cysts are the remnants of the Wolffian duct. The mesonephric (Wolffian) ducts begin to develop at 20-30 days of gestation and contribute to the development of the male reproductive excretory system that includes vas deferens, epididymis and seminal vesicles while they degenerate and remain as a vestigial system in the females.[3] Here we present a case of a large Gartner's cyst with the symptoms of dyspareunia and prolapsing vaginal mass, which was surgically excised.

\section{CASE REPORT}

Patient was a 33 yr. old female para 2 with previous 2 normal deliveries. Came to us with the chief complaints of dyspareunia and a prolapsing vaginal mass. Patient gave no history of difficulty in passing urine or stools.

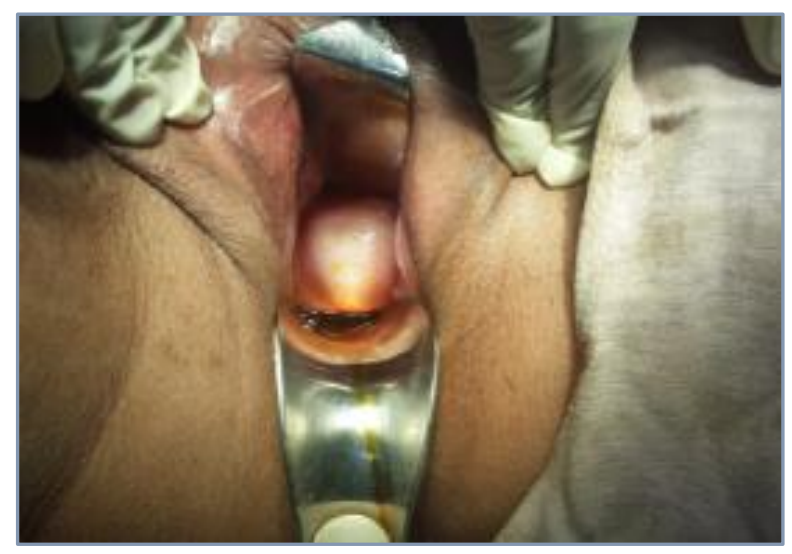

Per Speculum Examination showing Large Cyst

Financial or Other, Competing Interest: None.

Submission 13-11-2015, Peer Review 14-11-2015,

Acceptance 02-12-2015, Published 10-12-2015.

Corresponding Author:

Dr. Sumit H. Paranjpe,

44/101 "Amrut Vani" C.H.S. $15^{\text {th }}$ Rd.,

Chembur-400071, Mumbai.

E-mail:sumit9146@yahoo.com

DOI:10.14260/jemds/2015/2448
No other history of any menstrual irregularity or any kind of vaginal discharge. Per speculum examination showed a large $S$ shaped cyst originating from the proximal vagina with a size of about $6 \times 7 \times 5 \mathrm{~cm}$. Per vaginal examination revealed the origin of the mass from the upper right lateral wall of the vagina and cystic is nature. The ultrasound showed a large anechoic fluid filled cyst of $6 \times 7 \mathrm{~cm}$ that was distinct from the uterus. Her laboratory routine investigations were within normal limits. Surgical excision was done in lithotomy position. Due to dense adhesion between the cyst wall and the vagina, complete excision was not possible and hence marsupialization of the remaining cyst was done. Fluid from the cyst and cyst wall was sent for histopathological examination, which showed non-mucin secreting low columnar and cuboidal epithelium, which are consistent with Gartner's cyst. Patient did not have any complaints at threemonth post-operative follow-up.

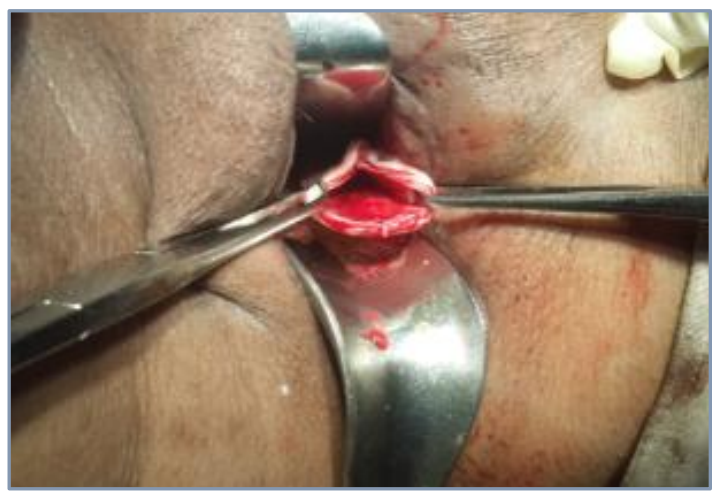

Cavity of Cyst Opened with Separation of Cyst Wall in Progress

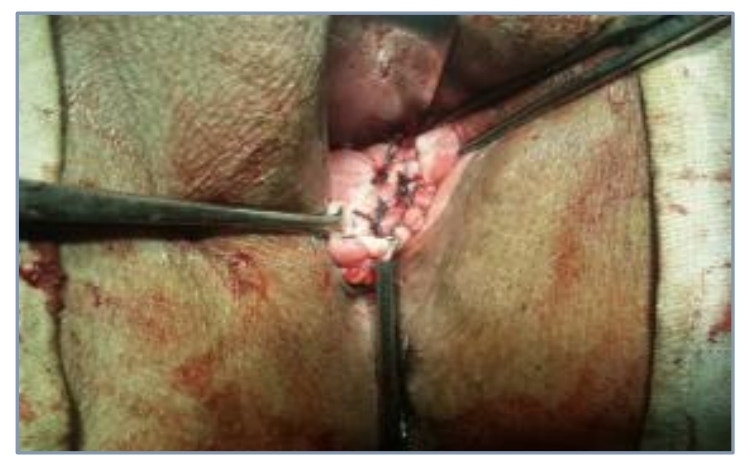

Marsupialisation of Remaining Cyst Done 


\section{DISCUSSION}

Classically, Gartner's cysts are solitary, S shaped unilateral, about $2 \mathrm{~cm}$ in diameter and are located in the antero-lateral vaginal wall of the proximal one-third of the vagina. ${ }^{[4]}$ But in this case, the cyst was quite large about $6 \times 7 \mathrm{~cm}$ in the right upper lateral vaginal wall. Only in exceptionally rare and few isolated cases, there has been a malignant transformation reported.[5]

Other acquired cysts in the vagina include endometriotic cysts, mucinous vestibular cysts, Bartholin cysts and Skene duct cysts. Congenital cysts may be derived from urogenital sinus or from mesonephric (Gartner cyst) or paramesonephric (Mullerian cyst) remnants. Gartner duct cysts sometimes are also associated with a variety of developmental abnormalities of the urinary tract.[6]

When the cysts enlarge, they may be mistaken for a cystocele or an urethral diverticulum. The largest Gartner duct cyst reported till now is measured $16 \mathrm{~cm} \times 15 \mathrm{~cm} x 8 \mathrm{~cm} .{ }^{[7]}$

Many Gartner duct cysts drain spontaneously or are aspirated. If surgical treatment is indicated, marsupialisation or simple transvaginal excision is usually adequate. ${ }^{[8]}$

Thus, as we can see from this case a Gartner's cyst can grow quite larger to cause symptoms such as dyspareunia. As in this case a part of the cyst wall could not be removed and a simple marsupialization was done which gave good results and a symptom-free post-operative period.

\section{REFERENCES}

1. Heller DS. Vaginal cysts: a pathology $r$ J Low Genit Tract Dis 2012;16:140-144.

2. Lee HS, Joo KB, Song HT, et al. Relationship between sonographic and pathologic findings in epidermal inclusion cysts. J Diagn Med Sonog 2008;24:344.

3. Akkawi R, Valente AL, Badawy SZA. Large mesonephric cyst with acute adnexal torsion in a teenage g Journal Pediatr Adolesc Gynecol 2012;25:143-145.

4. Pradhan S, Toban H. Vaginal cysts: a clinicopathological study of 41 cases J Gynecol Surg 2009;24:75.

5. Anne-Sophie Bats, Ulrike Metzger, Marie-Aude Le FrereBelda, Marie Brisa, Fabrice Lecuru. Malignant transformation of Gartner's cyst. Int J Gynecol Cancer 2009 Dec;19(9):1655-7.

6. Schmidt WA. Pathology of the vagina, In: Fox H, Wells M, eds. Haines and Taylor Obstetrical and Gynecological Pathology. 5th ed. London, UK: Churchill Livingstone; 2003:147.

7. Hagspiel KD. Giant Gartner duct cyst: magnetic resonance imaging findings. Abdom Imaging 1995;20(6):566-8.

8. Fan EW, Cheng TC, Chiu AW, et al. Pyonephrosis and urinary retention secondary to a large Gartner's duct cyst associated with single ectopic ureter in a pregnant woman. BJU Int 2002;89(1):136-7. 